
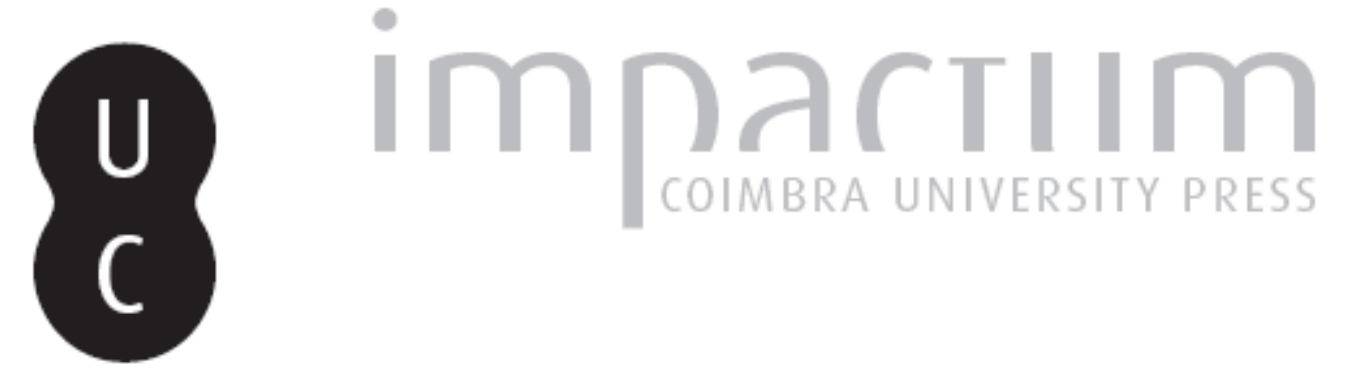

Os «mourões» do Rossio de Abrantes: afinal, a ponte romana era um cais... do séc. $\mathrm{XIX}$

Autor(es): $\quad$ Silva, Joaquim Candeias

Publicado por: Imprensa da Universidade de Coimbra

URL persistente:

URI:http://hdl.handle.net/10316.2/45659

DOI:

DOI:https://dx.doi.org/10.14195/1647-8657_24_8

Accessed : $\quad$ 26-Apr-2023 15:42:07

A navegação consulta e descarregamento dos títulos inseridos nas Bibliotecas Digitais UC Digitalis, UC Pombalina e UC Impactum, pressupõem a aceitação plena e sem reservas dos Termos e Condições de Uso destas Bibliotecas Digitais, disponíveis em https://digitalis.uc.pt/pt-pt/termos.

Conforme exposto nos referidos Termos e Condições de Uso, o descarregamento de títulos de acesso restrito requer uma licença válida de autorização devendo o utilizador aceder ao(s) documento(s) a partir de um endereço de IP da instituição detentora da supramencionada licença.

Ao utilizador é apenas permitido o descarregamento para uso pessoal, pelo que o emprego do(s) título(s) descarregado(s) para outro fim, designadamente comercial, carece de autorização do respetivo autor ou editor da obra.

Na medida em que todas as obras da UC Digitalis se encontram protegidas pelo Código do Direito de Autor e Direitos Conexos e demais legislação aplicável, toda a cópia, parcial ou total, deste documento, nos casos em que é legalmente admitida, deverá conter ou fazer-se acompanhar por este aviso.

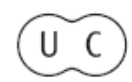


FACULDADE DE LETRAS

INSTITUTO DE ARQUEOLOGIA

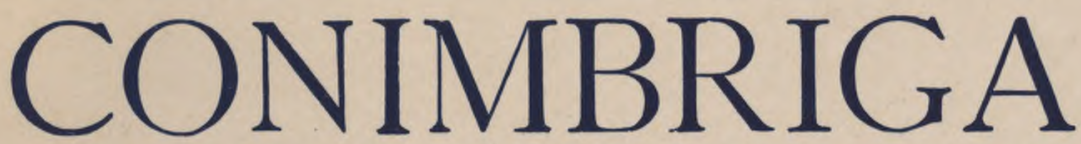

VOLUMEXXIV

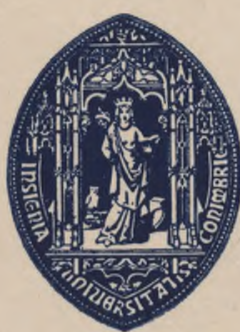

UNIVERSIDADE DE COIMBRA

1985 
Joaquim Candeias Silva

Professor do Ensino Secundário

OS «MOURÕES» DO ROSSIO DE ABRANTES — AFINAL, A PONTE

ROMANA ERA UM CAIS... DO SÉC. XIX

«Conimbriga», XXIV (1985), p. 17 7-185

Resumo: Uma planta recentemente descoberta no Gabinete de Estudos

Arqueológicos de Engenharia Militar veio provar que os restos duma ponte sobre o rio Tejo, em Abrantes, não remontavam à época romana, como se chegara a pensar, mas sim ao período das invasões napoleónicas.

RÉSumé: On vient de découvrir, dans les archives militaires portugais, des dessins d'un vieux pont sur le Tage, à côté de la ville d'Abrantes: il s'agit, en effet, d'un pont bâti à l'époque das invasions napoléoniques au Portugal (début du XIX ème siècle), qui n'a rien $d v$ romain. 
(Página deixada propositadamente em branco) 


\section{OS «MOURÕES» DO ROSSIO DE ABRANTES -AFINAL, A PONTE ROMANA ERA UM CAIS... DO SÉC. XIX}

Aquele extenso renque de pegões a descair sobre o Tejo, na sua margem esquerda, sempre me causou engulhos quanto à sua origem e finalidade, desde que, em 1969, arribei ao Rossio ao Sul do Tejo. A mim como, decerto, a quase todas as pessoas que, de qualquer forma, se interessaram pela arqueologia ou pela história da região $(\lambda)$.

P) Sem pretender, de modo algum, fornecer uma listagem exaustiva, eis algumas:

- Henrique M. V. M. Carval ho, em Monografia do Concelho de Abranles, Abrantes, 1937, exemplar dactilografado, em poder da Câmara Municipal de Abrantes. A págs. 56, em legenda a uma foto dos «mourões», pergunta: «Serão estes os restos da via Scallabis-Emerita?» E acaba por responder afirmativamente, acrescentando que é flagrante a sua semelhança com os restos da antiga ponte romana de Mértola sobre o Guadiana». (A propósito deste falso confronto, vide D. Fernando de Almeida, As ruínas da chamada ponte romana de Mértola, «Madrider Mitteilungen», 17, 1976, p. 295-304).

- Diogo Oleiro, Pontes e vias romanas, «Jornal de Abrantes», 29-12-1942, com foto da «ponte romana do Tejo». Iрем, Abrantes, Cidade Florida, 1952, p. 76.

- Gen. João de almeida, Roteiro dos Monumentos Militares Portugueses, XI, Lisboa, 1946, p. 249: a estrada romana principal passava pelo Rossio, «onde ligava, por uma ponte monumental sobre o Tejo, com a fortaleza romana de Abrantes».

- Gustavo M. Sequeira, Inventário Artístico do Distrito de Santarém, Lisboa, 1949, p. 14: «Rossio de Abrantes: Monumentos romanos (...)».

- Mário SAA, As Grandes Vias da Lusitânia, tomo I, Lisboa, 1957, p. 164-168: «(...) não são obra romana, nem ponte», mas «plano indi- 
De tudo the chamaram: ponte, ponte inacabada, cais, ponte-cais, plano inclinado de estaleiro naval, sistema de elevação de águas para rega. Fundadores também não lhe faltaram: romanos, mouros, portugueses dos primórdios da nacionalidade. Mais prudenmente andou o legislador, que o classificou como imóvel de interesse público (Dec.-Lei 251, de 3-6-1970), ao designá-lo muito simplesmente por «conjunto de pilares existentes na margem esquerda do rio Tejo».

Não há dúvida que Marc Bloch tinha razão em afirmar que as actividades humanas do passado são de natureza a seduzir a imaginação dos homens, sobretudo quando, graças ao distanciamento no tempo, se enfeitam com as subtis seduções do que é estranho ( $\left.{ }^{2}\right)$.

Até que, em Outubro passado, um homem de Abril, também investigador de temas histórico-militares — o major dr. Fernando Salgueiro Maia - trouxe a público ( $\left.{ }^{3}\right)$ a cópia de um documento, que descobrira no Gabinete de Estudos Arqueológicos de Engenharia Militar (= GEAEM) e que contém, nem mais nem menos, a planta da construção dos ditos pegões, se bem que elaborada a posteriori.

Trata-se de um longo desdobrável de $1,94 \times 0,30 \mathrm{~m}$, utilizando no geral uma «escalia de 200 palmos» (correspondente à escala

nado de estaleiro naval» e «devemos situá-la nos reinados dos primeiros reis de Portugal».

- J. M. Bairrão Oleiro, Uma estátua romana na quinta da Baeta (.Rossio ao Sul do Tejo, Abranles), «Humanitas», vol. XIII/XIV, 1962, p. 367: «(...) uma discutida construção romana que tem sido considerada como ponte».

- J. D. Santa-Rita Fernandes, Abranles Cidade, 1966(?), p. 18 e 27, com foto dos «pegões da ponte-cais romana».

(2) Cf. Marc Bloch, Introdução à História, Lisboa, 1965, p. 14.

(3) No colóquio realizado na Biblioteca Pública de Abrantes, a 24-10-84, subordinado ao tema «Abrantes na Estratégia Militar».

Aproveito para agradecer ao responsável pelo Arquivo Histórico do Concelho de Abrantes, que conseguiu obter do conferente uma cópia do documento original em tamanho natural, as facilidades concedidas para o seu estudo. 
métrica de 1:225, aprox.), na qual sâo postos em evidência o alçado e planta global da PONTE MELITAR de barcas que foi Estabelecida no Tejo da Villa de Abranles em (a partir de) Dezenbro de 1808.

À esquerda, aparece, numa espécie de caixa e em «escalia de 40 palmos (4 vezes maior que a do alçado e planta geral para milhor percepçaõ)», o "Alçado intrior de hum pegaõ de estacaria», para exemplificar como era constituído o cais de madeira, «obra feita no Veraõ de 1809» sobre o areal da margem norte, «para servir de suplemento à Ponte de Barcas na ocazião das emchentes do Tejo». À direita, na mesma escala, lá está o «Alçado interior de hum pegaõ ou secçaõ», com a respectiva planta, para exemplificar a constituição do CAIS DA MARGEM SUL que foi «últimamente construido na Praia do Sul nos mezes de Setenbro, Outubro, e Novenbro de 1811, formado de pegões de pedra e cal, e madeira porcima, (...), fazendo hum segundo suplemento à Ponte de Barcas na ocazião das emchentes».

Sensivelmente a meio, vem uma «esplicaçaõ», para nos ajudar à interpretação das letras convencionais e, consequentemente, do funcionamento de todo o sistema: nela se assinala a «Praça para poderem virar os carros, e se arrumarem quando pela Ponte se encontrão opostamente», a «Levadiça para a entrada e sahida das embarcaçoens», as "Barcas que se vão metendo sobre as Rampas (...) e tirando à proporção que o Tejo Levanta ou abaxa», bem como as linhas das «agoas ordinarias», das «Cheias medianas» e das «grandes Cheias». Uma outra legenda, no canto inferior direito, esclarece-nos ainda que «Tanto esta Ponte como todas as mais que se tem estabelecido na Beira Baixa tem sido da Direcção do Coronel do Real Corpo de Engenheiros abaixo assignado (...) Manoel de Souza Ramos». Datada: «Quartel de Abrantes 13 de de 1812 ».

O desenho revela, pois, um trabalho de bastante imaginação e apreciável primor técnico, que teria por objectivo principal estabelecer militarmente a ligação entre o norte e o sul do Tejo, as Beiras e o Alentejo, tendo em conta a necessidade de defesa do centro do País face às invasões francesas. Abrantes, um importante núcleo populacional com tradições de guardilp da linha do Tejo devido ao seu posicionamento geo-estratégi $<\wedge$, que 
já tinha estado inclusivamente no itinerário de $\operatorname{Junot}\left({ }^{4}\right)$, era, sem dúvida, o local privilegiado para a instalação de uma obra de engenharia desta envergadura.

Como corolário do que fica dito, convém esclarecer que todos os demais testemunhos da época (e não só) se ajustam perfeitamente, como peças de um mesmo puzzle. Consideremos três deles:

- O testemunho de Manuel A. Morato, autor da mais antiga e completa monografia de Abrantes $\mathrm{j}\left({ }^{5}\right)$ : «No princípio do ano de 1809 , mandou o Governo fortificar esta Vila, incumbindo os trabalhos ao Capitão de Engenheiros do Exército Inglês, Pactom, debaixo da inspecção do Coronel de Engenheiros do Exército Português, Manuel de Sousa Ramos, que foi o primeiro Governador Militar da Praça, depois da Restauração» (da soberania portuguesa nesta vila a $17-8-1808$ ).

«...No mesmo ano de 1809 , foi novamente restabelecida $\left(^{6}\right)$ a ponte de barcas sobre o Tejo para, ao abrigo da artilharia da Praça, facilitar a passagem e comunicação entre os nossos exércitos do norte e sul. O Governo, conhecendo a importância da posição topográfica desta Vila com relação às Províncias da Beira e Alentejo, classificou-a Praça de primeira ordem. (...) Durante toda a Guerra Peninsular, foi esta Praça o principal depósito de munições de guerra, víveres e ambulâncias».

(4) Cfr. J. Candeias Silva, Junot em Abrantes, «Notícias de Abrantes», n.o io, 28-11-1980. Recorda-se que ao ambicioso comandante da $1 .{ }^{a}$ invasão francesa concedeu Napoleão o título de Duque de Abrantes, por certo em atenção aos seus «feitos» nesta (então) vila.

${ }^{(5)}$ Memória Histórica da Notável Vila de Abrantes, edição da Câmara Municipal de Abrantes, com anotações de Eduardo M. T. Campos, Torres Novas, 1981, p. 154. Morato, que nasceu precisamente no ano da construção do cais, redigiu esta obra ao longo do ano de 1860, socorrendo-se principalmente de documentos que foi consultando no arquivo da C.M.A. e que ainda hoje existem.

$\left(^{6}\right)$ A primeira ponte de barcas, terá sido construída por volta de 1730 , um pouco acima da actual ponte ferroviária (cf. Morato, op. cit., nota 210, e Santa-Rita Fernandes, op. cit., p. 51). Outras, entretanto, lhe sucederam, nomeadamente a que, a partir de 1797 , entestava na base do Cabeço do Caneiro, um pouco abaixo da foz do rio Torto. 
- Os mapas militares da vila e arredores de Abrantes, de 1797, 1801 e 1817, existentes no $\operatorname{GEAEM}\left({ }^{7}\right)$ : No primeiro, é bem nítida a inexistência de quaisquer pegões entre a chamada Pedreira das Argolas e o Rossio Velho ou «Banda d'Além», embora se distinga já um corredor de ligação à «Estrada do Gavião». No segundo, também ainda lá não estavam, continuando ao serviço a ponte do Caneiro, a jusante. Mas já no terceiro, obviamente, eles lá estão, no sítio próprio e com direito a legenda. A ponte, essa é que, alterada a situação conjuntural que a fizera nascer, desapareceu, engolida talvez por alguma cheia do rio.

- Desapareceram as barcas, assim como todo o travejamento de madeira de ambos os cais, mas deveria manter-se parte da estacaria da margem norte. E, efectivamente, há cerca de quatro anos, quando um industrial areeiro fez deslocar as suas máquinas de extracção para o local e começou aí a desassorear o rio, «punha-se a descoberto um duplo renque de toros de pinho, alinhados na direcção da chamada «ponte-cais», cravados na areia virgem a espaços curtos e a não muita profundidade» ( ${ }^{8}$ ). Era óbvio. $\mathrm{O}$ estranho era que aparecessem mais pegões da ponte... romana 1

Resta apenas uma pequena dúvida por resolver: o testemunho deixado em 1571 por Francisco d'Olanda, que tantas vezes tem sido invocado - «Fizeraõ (os romãos) outra Ponte Magnifica acima daBrãtes, onde estaõ os pégoês e mõtes de pedra $(. ..) \gg\left({ }^{9}\right)-$ e que me levou a afirmar, noutra oportunidade, que seria ele o principal «padrinho» da pseudo-ponte romana de Abrantes $\left({ }^{10}\right)$. A que «ponte» e «pégões» Olanda se quereria referir?

Logicamente que não poderiam ser os do Rossio, que até nem ficam «acima» de Abrantes, mas ao sul e, portanto, abaixo.

(7) Todos já publicados pelo arq. ${ }^{\circ}$ José D. Santa Rita Fernandes, op. cit., respectivamente a p. 87,30 e 42 .

(8) J. C. S., «Notícias de Abrantes», n. ${ }^{\circ} 3,10-10-1980$, p. 9.

(9) Da Fabrica que faleçe a Çidade de Lisboa, Códice da Biblioteca da Ajuda, cap. VII, fl. 19 v. ${ }^{\circ}$, Ed. de Jorge Segurado, Lisboa, 1970, p. 104.

${ }^{(10)}$ Epigrafia romana de Abrantes - Quatro textos em questão, comunicação apresentada às 1. ${ }^{\text {as }}$ Jornadas de Estudos Epigráficos da Beira, «Trebaruna», Castelo Branco, 1981, p. 15. 
Salvo melhor opinião, penso que o arqueólogo-artista de Quinhentos poderia ter-se querido referir aos pegões daquele que tem sido considerado um aqueduto, que abasteceria a antiga povoação de Alvega (a Aritium Vetus dos Romanos) e que ainda se pode observar na margem esquerda do Tejo, próximo de Casa Branca.

Mais remotamente, admito ainda que quisesse aludir à chamada «ponte-represa romana» de Olho de Boi (Alferrarede). É que, no fundo, talvez nem o próprio Olanda soubesse localizá-los com precisão, pois se baseou numa informação antiga fornecida por terceiros $\left({ }^{\mathrm{n}}\right)$.

Em suma, só uma conclusão se impõe, incontestável: a tão decantada «ponte monumental romana que servia Tubucci» foi, afinal, um cais, dos princípios do séc. xix, feito para servir de apoio a uma ponte militar de barcas, por ocasião das cheias.

Mas, como foi possível - perguntarão muitos — em tão pouco tempo instalar-se tamanha confusão ? Como foi possível criar-se, entre a população rossiense por exemplo, uma tradição tão forte e tão rotundamente falsa?

Há que considerar, primeiramente, que o Rossio é uma povoação recente. À data da construção do cais - informa-nos Morato (12) - contava apenas duas ou três casas abarracadas... Depois, foi crescendo, mas os novos habitantes e seus descendentes, gente modesta, laboriosa e de bastante mobilidade, não terão naturalmente chegado a adquirir uma autêntica consciência histórica (13).

Em segundo lugar, o funcionamento da ponte terá sido muito restrito (era militar) e a sua duração muito efémera. Como ficou dito atrás, em 1817 — apenas cinco anos depois da construção dos pegões - ela já não funcionava.

Depois, há ainda que analisar o quadro geral da época em que o mito se terá forjado e desenvolvido — princípios do

(n) «...e esta quisera redeficar o liante Dõ Fernãdo q Déos tê, següdo dixe a meu Pay Ant. ${ }^{\circ}$ Dolanda tãbê q Deos tem» (ibidem).

(12) Op. cit., p. 155, nota XLVII.

(13) Sobre a evolução económica e social do Rossio ao Sul do Tejo, cf. Jorge Gaspar, os portos fluviais do Tejo, «Finisterra», vol. V, n. ${ }^{\circ} 10$, Lisboa, 1970. 
séc. $\mathrm{xx}\left({ }^{14}\right)$ - bem como a mentalidade dominante entre os pretensos historiadores abrantinos de então: homens muito esforçados sim, mas arreigados a uma visão marcadamente bairrista e mais ou menos romântica da História, utilizando métodos e técnicas por vezes bem pouco rigorosos de reconstituição do passado e cedendo, frequentemente, ao capricho imaginativo e à arbitrariedade, um pouco ainda à maneira dos sécs. xvi/xvıI. O aproveitamento do manuscrito de Francisco d'Olanda fez o resto.

$\mathrm{O}$ fenómeno, aliás, não é inédito, infelizmente. Acaso não se desmitificaram já tantos episódios lendários, tantos casos de atribuição de épocas remotas a monumentos ou materiais recentes ? Em Abrantes mesmo, não se desmontaram já quatro epígrafes, falsamente imputadas aos Romanos com o nítido propósito de sobrevalorizar o passado do burgo ? $\left({ }^{15}\right)$.

Este é, portanto, e apenas, mais um caso exemplar de falsa romanização, a juntar a muitos outros $\left({ }^{16}\right)$. Sinal de que a História, a Arqueologia, continuam atravancadas de muitas lendas disparatadas, de muito empirismo disfarçado de senso comum. Que é preciso rejeitar. Quanto antes.

(14) O mais antigo documento conhecido onde os pegões surgem assinalados como ponte romana (ruínas), é uma planta arqueológica da região de Abrantes, na escala de 1:50 000, que foi oferecida por um oficial superior abrantino ao Arquivo Histórico Militar, antes de 1933 (Margarida Ribeiro, «O Arqueólogo Português», nova série, vol. V, 1965, n. 449-452).

Não vem a referida planta assinada, nem datada, nem a autora do artigo avança qualquer hipótese a esse respeito. Contudo, relacionando a qualidade dos achados nela registados com determinadas ocorrências entretanto verificadas em Abrantes, creio ter fundadas razões para a datar à volta de 1920 e situar entre 1910-1915 a génese e propagação do mito.

(15) Ver nota 10.

(16) Só na zona de Abrantes podemos citar mais uma meia dúzia de pontes, de diversas épocas, que ainda são vulgarmente atribuídas aos romanos (a planta arqueológica, atrás citada, inclui duas delas). Mas há outros monumentos c outias facetas da história abrantina a precisarem crítica impiedosa e cerce - a identidade de Tubucci / Aurantes / Abrantes, por exemplo... 
EST. 1

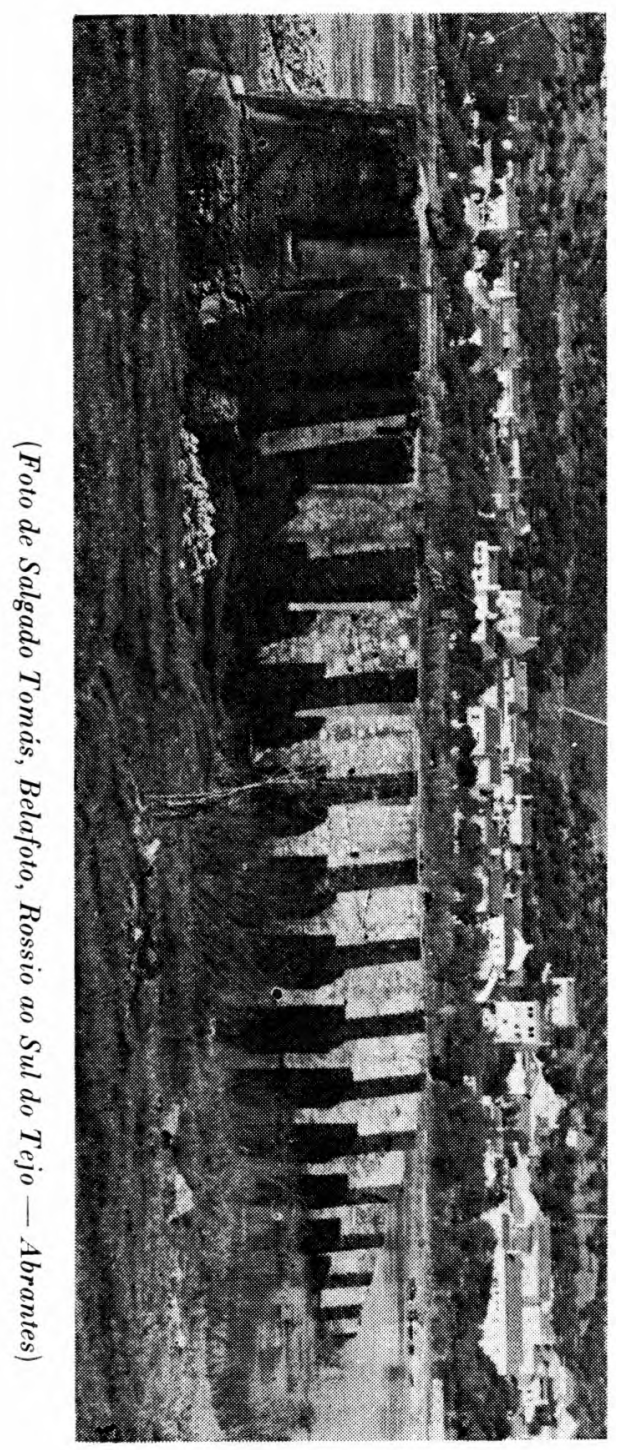


EST. 2

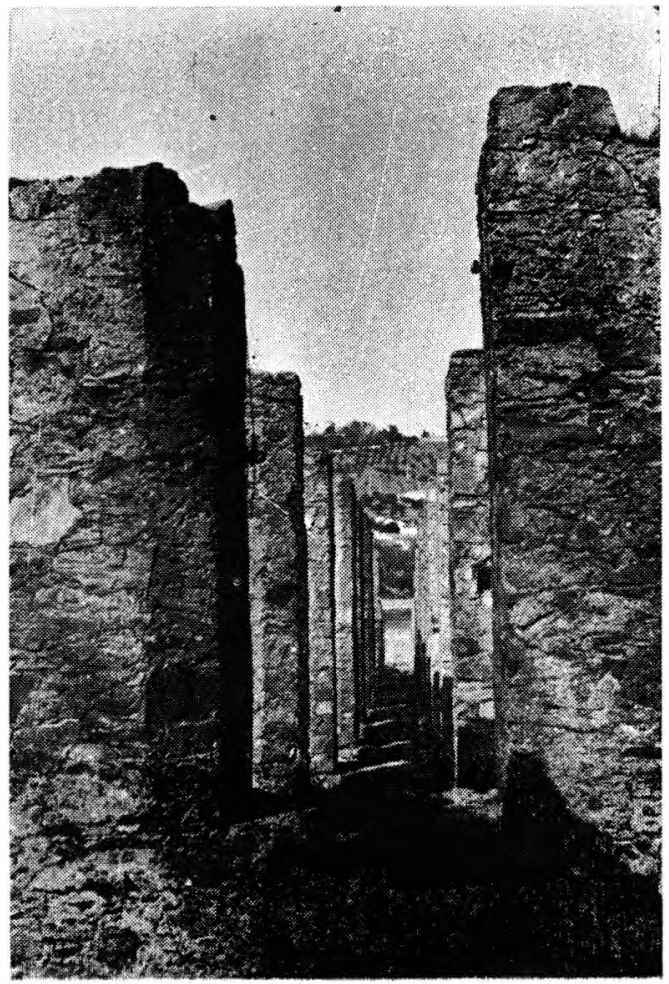

(Foto de Salgado Tomás, Belafoto, Rossio ao Sul do Tejo-Abrantes) 
(Página deixada propositadamente em branco) 
n

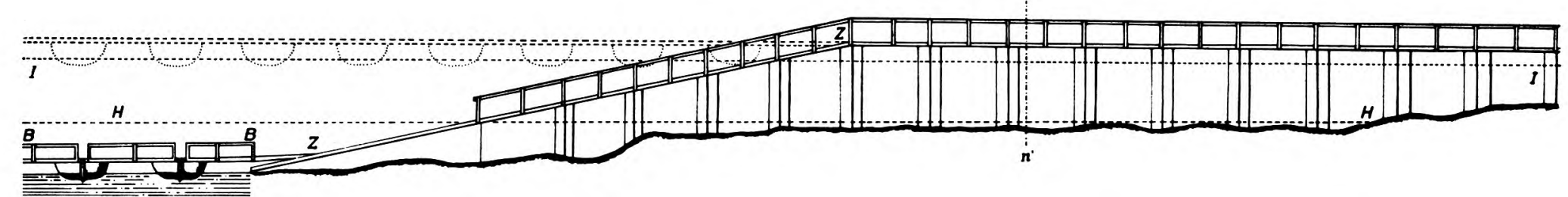

$\ldots$

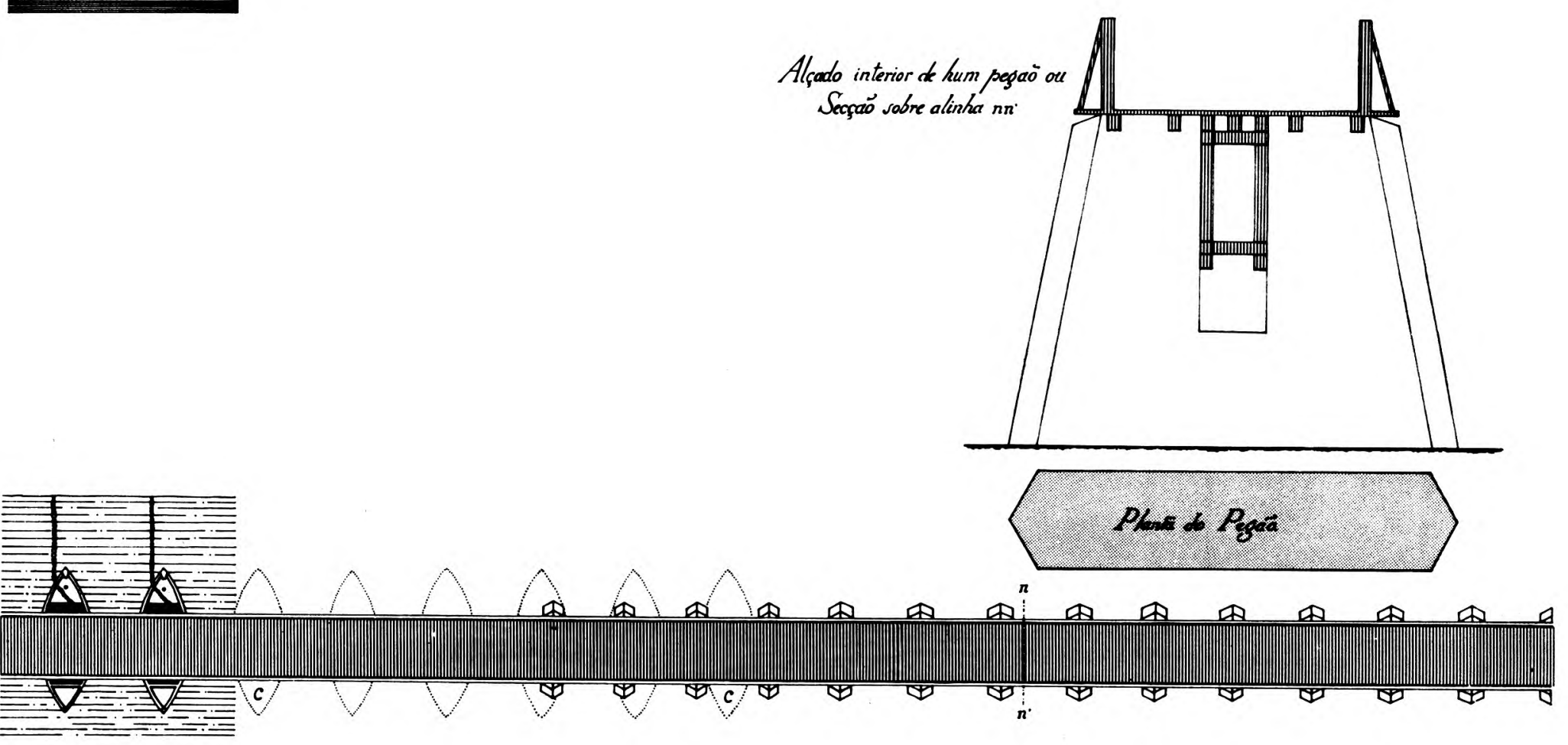

